\title{
O CONFRONTO ENTRE O PENSAMENTO PÓS-METAFÍSICO DE JÜRGEN HABERMAS E A NOVA METAFÍSICA DE LORENZ BRUNO PUNTEL
}

\author{
Adriano Messias Rodrigues ${ }^{1}$ \\ Luís Alexandre Dias do Carmo
}

\begin{abstract}
Resumo:
O presente artigo busca apresentar duas formas de entender a realidade nos dias de hoje, uma que consiste num pensamento situado e contextual, e outra que se trata de uma visão global da realidade em seus diversos setores e âmbitos. Em primeiro lugar, o pensamento pós-metafísico de Jürgen Habermas, que centralizando a análise na pragmática e na razão comunicativa, situa a questão da verdade num nível epistêmico, transcendental e dessa forma não consegue tematizar, de forma coerente e sistemática, uma teoria do mundo de forma objetiva e realista. Em segundo lugar, a Nova Metafísica de Lorenz B. Puntel, que entende a filosofia enquanto teoria universal que busca a verdade em sua investigação e na qual a semântica surge como dimensão central de articulação da unidade entre linguagem e mundo objetivo, a partir do desenvolvimento de uma nova metafísica, enquanto metafísica do Ser Primordial. Assim, este artigo pretende mostrar as diferenças entre as posições divergentes desses dois filósofos, a partir da tradição de pensamento de mais de dois mil anos que entende a filosofia enquanto teoria abrangente que trabalha as estruturas fundamentais da realidade enquanto tal.
\end{abstract}

Palavras-chave: Virada linguística. Pensamento pós-metafísico. Pragmática. Nova metafísica.

\section{THE CONFRONTATION BETWEEN JÜRGEN HABERMAS' POST-METAPHYSICAL THINKING AND LORENZ BRUNO PUNTEL'S NEW METAPHYSICS}

\begin{abstract}
:
This article seeks to present two ways of understanding reality today, one that consists of situated and contextual thinking, and the other that is a vision of the whole of reality in its various sectors and areas. First, Jürgen Habermas's postmetaphysical thought, which, based on the centrality of pragmatics and communicative reason, places the question of truth on an epistemic and transcendental level, failing to coherently and systematically thematize a theory of the world in a coherent way. objective and realistic. And, secondly, Lorenz B. Puntel's New Metaphysics, which understands philosophy as a universal theory that seeks the truth in its investigation and in which semantics emerges as a central dimension of articulation of the unity between language and the objective world, this from the development of a new metaphysics, as a metaphysics of the Primordial Being. Thus, this article intends to show the differences between the divergent positions of these two philosophers, based on the thought tradition of more than two thousand years that understands philosophy as a comprehensive theory that works on the fundamental structures of reality as such.
\end{abstract}

Keywords: Linguistic turn. Post-metaphysical thinking. Pragmatics. New metaphysics.

1 Mestre em Filosofia pelo Programa de Pós-Graduação em Filosofia da Universidade Federal do Ceará (UFC). Orcid: http://orcid.org/0000-0003-1597-3553. E-mail: adriano.messias2@gmail.com.

2 Doutor em Filosofia pela Universidade de São Paulo (USP). Orcid: http://orcid.org/0000-0002-8550-1802. E-mail: alexdiasdocarmo@yahoo.com.br. 


\section{INTRODUÇÃO}

Na sua obra Verdade e Justificação Jürgen Habermas pretende abordar questões teóricas que foram negligenciadas em sua obra desde a publicação de Conhecimento e Interesse e que versam sobre verdade e objetividade, realidade e referência, validade e racionalidade. Habermas desenvolve uma teoria consensual da verdade na década de 70 que depende do consenso discursivo entre os sujeitos capazes de ação e de fala, o qual evita a partir de assertibilidade ideal uma argumentação falsa, isso porque não considera o aspecto realista da verdade, ou seja, a relação irrenunciável entre linguagem e realidade. O que é expresso na linguagem não é linguagem, mas a linguagem é mediação irrecusável de tal modo que não temos a realidade sem linguagem, tese que nesta generalidade é comum a Habermas e a Puntel. Tome-se como exemplo, a tese defendida por Habermas de que a experiência perdeu sua autoridade epistêmica com a virada linguística, porque ela já é mediada linguisticamente, ou seja, em sua linguagem, ela já é filtrada pela linguagem de tal modo que linguagem e realidade se compenetram mutuamente de modo inextrincável.

Em Verdade e Justificação, Habermas irá fazer depender o seu conceito de verdade da própria relação aos objetos do mundo, ou seja, da realidade como totalidade de objetos. Ele reconhece o mundo objetivo como uma dimensão independente que é comum e partilhada por todos e que está na base do desenvolvimento das ações e discursos. Trata-se de um postulado sem o qual não seria possível nem discurso nem ação. Portanto, nesse nível, verdade implica referência a um mundo objetivo independente. Aqui se trata de crenças não questionadas, consideradas verdadeiras, que geram uma segurança incondicional de verdade, portanto, precedem, enquanto base, o discurso e as ações, não obstante, reconhecemos que Habermas não tematiza esse horizonte prévio com a devida propriedade. Consideramos que isso acontece por conta de suas opções pós-metafísicas, o que deixa obscurecido outro aspecto muito importante para pensar a realidade, que é a dimensão de articulação da conexão entre sentenças/proposições verdadeiras e o mundo objetivo.

Os problemas que levaram Habermas a abandonar sua antiga posição e desenvolver uma nova postura filosófica têm a ver agora com a verdade desligada conteudisticamente, ou seja, conceitualmente, pois ela transcende a justificação, mas não epistemologicamente, no nível dos discursos da justificação, porque apenas os objetos do mundo podem pretender objetividade (realismo epistemológico-pragmático). Neste sentido, as sentenças e proposições verdadeiras só podem pretender validade das suas pretensões discursivas, e isso, até que a realidade dos objetos do mundo não diga o contrário (fracasso performativo). Ao enfrentar o problema ontológico do naturalismo Habermas abre mão de uma teoria da verdade no sentido realista, dessa forma, consideramos que ele não tem como conciliar as questões da normatividade de um mundo da vida linguisticamente

\begin{tabular}{|l|l|l|l|l|}
\hline Gonista Dialectus & Ano 10 & n. 24 & Setembro - Dezembro 2021 & p. $12-33$ \\
\hline
\end{tabular}



estruturado e a contingência de um desenvolvimento histórico-natural das formas de vida socioculturais. Sobretudo, não consegue resolver a questão epistemológica do realismo, por não ter como conciliar o mundo objetivo que é pressuposto e reconhecido como independente pelos sujeitos de ação e de fala com a mediação ineliminável da linguagem. ${ }^{3}$

Puntel apresenta a proposta de uma nova Metafísica do Ser Primordial que contemple tanto os problemas do naturalismo, quanto do realismo e do gap entre sujeito e objeto, ou seja, linguagem e mundo objetivo, questões nas quais Habermas é alvo de profundas críticas. Ao “destranscendentalizar" o transcendental que agora não pertence mais ao mundo inteligível, e considerando-o constituído pelas práticas intersubjetivas no mundo da vida, destacamos que Habermas viu-se marcado pelos mesmos problemas que levaram Kant a articular a filosofia transcendental, quais sejam: o ceticismo e relativismo que pretendiam ser superados pela filosofia kantiana e que na pragmática formal de Habermas ganham uma nova roupagem como, por exemplo, o par transcendental a priori e a posteriori foi substituído pelo par pragmático mundo da vida e mundo objetivo.

Puntel entende filosofia dentro da tradição de pensamento que a considera como uma atividade humana que se ocupa de elaboração e exposição de teorias que buscam a verdade de sua investigação. Portanto, é um saber irrestrito e universal que abrange as estruturas fundamentais da realidade como um todo, no que leva ao entendimento de que o tema da investigação filosófica é o universo ilimitado do discurso. Neste sentido, uma teoria do Ser que será melhor desenvolvida aqui, deve abarcar a completude temática e as conexões entre os temas de forma coerente e inteligível. É o que propõe Puntel, ao elaborar uma definição de filosofia como teoria das estruturas universais do universo irrestrito do discurso, ou seja, o tema da filosofia é o grande dado ou tudo que é articulado linguisticamente ou enunciado por meio de uma sentença. Ao elaborar o conceito de Quadro teórico, enquanto explicitação da dimensão da teoricidade em seus componentes lógicos, semânticos e ontológicos que são pressupostos por toda e qualquer teoria que se pretenda plenamente determinada ${ }^{4}$, Puntel desenvolve uma filosofia que não parte do método dedutivo-axiomático, mas processual ou em rede em que os diversos quadros teóricos particulares vão ganhando em coerência e inteligibilidade à medida que vão sendo explicitados seus pressupostos teóricos até chegar à completa

\footnotetext{
3 Segundo C. França a interpretação pragmática da verdade em Habermas padece de uma indeterminação fundamental. Ela não consegue tematizar os elementos realistas e objetivos que constituem o conceito da verdade quando entendida de forma não epistêmica. A tentativa de romper com a cisão entre linguagem e mundo objetivo, seria expressão de uma inadequada metafísica. "Se aquilo que torna as sentenças verdadeiras no mundo não está ao alcance da pragmática formal, sua tentativa de dar conta das intuições realistas presentes nas práticas comunicativas cotidianas é inexequível, e sua concepção pragmática da verdade permanece indeterminada porque falta a esta os elementos teóricos que legitimam a distinção entre verdade e justificação". Cf. FRANÇA, 2017, p. 264.

4 Cf. OLIVEIRA, 2019a, p. 302.
}

\begin{tabular}{|c|c|c|c|c|}
\hline Qovista Dialectus & Ano 10 & n. 24 & Setembro - Dezembro 2021 & p. $12-33$ \\
\hline
\end{tabular}



determinação do Quadro Sistemático mais geral. Por isso, a primeira tarefa da filosofia é explicitar seus pressupostos teórico-metodológicos como condições irrenunciáveis de expressão das coisas mesmas, sob pena, de nossa argumentação se tornar incompreensível, vaga e indeterminada. Estes pressupostos estão organizados em três planos: estruturas formais (lógicas e matemáticas) e estruturas de conteúdo (semânticas e ontológicas).

Somente a partir de uma nova consideração da linguagem em seus componentes lógicos, matemáticos, semânticos e ontológicos é possível, segundo Puntel, superar estas dicotomias que marcam a filosofia transcendental e a postura pós-metafísica habermasiana. Uma vez tematizados os componentes da linguagem que são os componentes irrecusáveis da teoria, Puntel se pergunta a respeito da adequação da semântica e da ontologia tradicionais. Ele mostra que a ontologia tradicional, baseada no princípio de composicionalidade, é insustentável, porque está fundada na estrutura sujeito e predicado que está baseada na categoria central de substância ${ }^{5}$ que é algo que depende dos atributos que lhe são atribuídos pelo sujeito, logo quando se retira estes atributos não sobra nada a não ser, uma entidade vazia e ininteligível e a filosofia não pode se basear em algo assim. Portanto, Puntel irá fundar a sua nova semântica numa versão forte do princípio do contexto de Frege que diz que o sentido das sentenças, não se dá pelos seus componentes subsentenciais, mas pela estrutura da sentença enquanto configuração de sentenças primas que quando expressam os fatos do mundo são verdadeiras e denominadas de proposições primas, pois expressam a única categoria ontológica aceita na filosofia de Puntel, a categoria de fato primo ${ }^{6}$. Dessa forma, temos uma nova semântica e uma nova ontologia baseadas não na categoria de substância e na estrutura sujeito e objeto, mas na categoria de configuração de sentenças/proposições e na estrutura basal de fatos primos. Puntel propõe uma dimensão oniabrangente da realidade que surge como o novo elemento de uma teoria filosófica: seu conteúdo, seu tema, pois todo empreendimento teórico é sempre empreendimento sobre algo, sobre um tema. Para Puntel, o último e decisivo conteúdo, ou tema, o Ser enquanto completude temática e plenamente explicitada em seus componentes e relações estruturais. Noutras palavras, a dimensão abrangente que abarca tanto a linguagem/sujeito/espírito quanto o mundo/realidade/natureza. Daí o título do livro: Estrutura (linguagem e estrutura) e Ser (universo do discurso) que significa que a dimensão da linguagem pertence ao conceito de estrutura e o termo Ser significa o universo ilimitado do discurso que está na base de toda a filosofia sistemática-estrutural de Puntel $^{7}$. Esta dimensão última e decisiva abarcaria tanto a dimensão da linguagem, quanto a dimensão do mundo e que seria a dimensão do Mundo (com "M" maiúsculo),

5 PUNTEL, 2008, p. 91.

6 OLIVEIRA, 2014, p. 236.

7 PUNTEL, 2015, p. 55.

\begin{tabular}{|l|l|l|l|l|}
\hline Qenista Dialectus & Ano 10 & n. 24 & Setembro - Dezembro 2021 & p. 12 - 33 \\
\hline
\end{tabular}



pois somente assim, se poderia superar o dualismo e refletir sobre a relação entre sujeito e objeto e superar a postura pós-metafisica de Habermas e o ceticismo e o relativiso vigentes em seu pensamento. ${ }^{8}$

\section{DESENVOLVIMENTO}

\subsection{A virada linguística a partir de uma visão pós-metafísica e pragmática}

Para Puntel, Habermas tem uma visão bastante limitada da ontologia clássica e medieval, ou seja, da filosofia do ente enquanto ente, por não enfrentarem questões tão caras à sua filosofia como a problemática da subjetividade e da reviravolta linguística. Além disso, quando se refere à metafísica, se restringe ao ponto de vista pós-kantiano. Dentre os motivos que justificam a superação da metafísica, para Habermas, temos os seguintes: o surgimento da racionalidade procedimental das ciências, a historificação da razão pelas ciências histórico-hermenêuticas e a virada linguística na filosofia. Entretanto, um dos motivos principais para a postura pós-metafísica de Habermas é o que ele chama de uma deflação do extra-cotidiano ${ }^{9}$ que é a sua crítica à filosofia transcendental de Kant que fala não dos objetos, mas do nosso modo de conhecimento a priori dos objetos. ${ }^{10}$ Isso coloca em primeiro plano a análise das categorias subjetivas do nosso aparato cognitivo, o que conduz à posição de que se relegue ao nível de uma incognoscibilidade insuperável, os dados do mundo objetivo, daí a relação de dependência da prática em relação à teoria. Com a virada pragmática na concepção de linguagem, esta situação sofre uma mudança radical - em virtude da relevância dos contextos cotidianos de ação e comunicação -, colocando como central para a reflexão o conceito de mundo da vida. Isso dá-se dessa forma porque a razão agora é uma forma de justificação pública (razão comunicativa) centrada nas regras discursivas e nas pretensões de validade levantadas pelos sujeitos linguísticos em suas práticas no mundo da vida. O tema central da filosofia passa a ser a interação social das práticas quotidianas e a justificação das normas de deliberação pública das práticas comunicativas do mundo da vida.

\footnotetext{
8 Para Juliano Cordeiro há em Habermas um déficit ontológico e metafísico. “... há, em Jürgen Habermas, um déficit ontológico (a falta de uma teoria dos entes) e metafísico (a falta de uma teoria do Ser) em sua filosofia. O pensamento de Habermas se reduziria, a nosso ver, à pragmática, não deixando espaço para o aprofundamento de questões ontológicas e metafísicas, que o próprio Habermas sugere implicitamente”. OLIVEIRA, J., 2018, Contracapa. Uma questão que poderíamos levantar nessa consideração do pensamento de Habermas é: se há espaço e que tipo de reflexão Habermas elabora, "postula" sobre a realidade que se diferencia da má metafísica?

9 PUNTEL, 2013, p. 182.

10 OLIVEIRA, 2019a, p. 292.
}

\begin{tabular}{|l|l|l|l|l|}
\hline Govista Dialectus & Ano 10 & n. 24 & Setembro - Dezembro 2021 & p. $12-33$ \\
\hline
\end{tabular}


A filosofia transcendental teve como modelo paradigmático o pensamento de Kant, que tinha nas estruturas cognoscentes do sujeito a fonte de legitimação do nosso saber dos fenômenos. Uma forma de radicalização deste paradigma foi a fenomenologia de Husserl, cujo entendimento tratava o conhecimento como uma correlação entre as formas de doação dos objetos e as nossas vivências ou atos intencionais da consciência. "Assim, as coisas mesmas não são objetos no sentido de uma 'posição transcendente de ser', mas o que é intuído na satisfação de atos intencionais". ${ }^{11}$ Neste modelo de filosofia, o que vale é o primado da intuição, ficando relegado, ao segundo plano, o nível das teorias e argumentações válidas.

Aqui se aprofunda a separação entre sujeito e objeto, porque o conhecimento ainda está no nível profundo da consciência, ainda que entendida enquanto lugar privilegiado da intuição. Também é onde se dá a correlação entre os atos intencionais e o sentido do intendido, ou seja, como fonte de originariedade ou fonte última de doação de sentido. Segundo Habermas apud Oliveira (2019b, pp. 18-19), uma crítica que podemos fazer ao primado da intuição é que na própria doação do objeto existem elementos linguísticos. E que, assim, não temos acesso ao objeto da experiência de forma pura, mas mediado linguisticamente.

Neste sentido, passa para o centro da consideração filosófica não a análise intencional dos objetos da consciência, mas a acareação das pretensões de validade presentes na nossa linguagem sobre o mundo. Aqui se situa o novo paradigma de configuração da filosofia enquanto reviravolta linguística, ou seja, a partir de agora, entendemos a própria experiência pela imbricação entre linguagem e realidade e o nosso conhecimento, por sua vez, como análise pragmática (acareação de pretensões de validade) da linguagem. Enfim, nossa experiência é mediada linguisticamente e não existe nada que nos seja dado fora da esfera conceitual ou linguística. A interpretação que Puntel faz da reviravolta linguística diverge profundamente da concepção pragmática de Habermas ${ }^{12}$, pois, para ele, a demonstração se dá no nível semântico-ontológico e, portanto, no nível expositivo de uma teoria filosófica e não na comunicação entre falantes. Puntel, por sua vez, entende a centralidade da linguagem a partir da exposição rigorosa de seus pressupostos lógicos, semânticos e ontológicos. E, também, da superação do abismo entre linguagem e mundo por meio de uma nova teoria semântica e de uma nova ontologia que se articula em primeiro lugar por uma compreensão de linguagem não em primeiro lugar como uma produção do ser humano, mas como a instância universal de expressão

11 OLIVEIRA, 2012a, p. 18.

12 Puntel faz uma longa análise do pensamento pragmático de Habermas, especialmente no que ele considera de mais deficiente na sua filosofia que é a falta de uma definição clara do conceito de teoria. Para Puntel, uma teoria genuína funciona a partir de um operador lógico universal que não possui elementos extra-teóricos que possam interferir na sua elaboração. Neste sentido, Puntel identifica como maior defeito de Habermas, identificar as estruturas e práticas comunicativas do mundo da vida como a base fundamental para desenvolver uma reflexão filosófica. Sobre este ponto, Cf. PUNTEL, 2013, p. 192. 

que corresponde à pressuposição de expressabilidade pressuposta por qualquer empreendimento teórico.

Segundo Habermas, o problema da virada linguística é que ela deu grande ênfase ao aspecto semântico ou as sentenças teóricas (declarativas) e não desenvolveu o aspecto pragmático ou da comunicação entre os falantes. "A teoria continua a gozar de um primado sobre a práxis, enquanto a representação goza de um primado sobre a comunicação. Quanto à analise semântica do agir, esta é dependente da análise cognitiva prévia” (HABERMAS, 2004, p. 8-9). Isso só é possível por meio de uma análise dos atos de fala constatativos, enquanto ações dos sujeitos no contexto do acordo intersubjetivo entre os sujeitos de fala e de ação. Para ele, não se separam as questões de significado (semântica) das questões de validade (pragmática), pois só posso compreender o significado de uma expressão linguística se sigo as regras do jogo linguístico e posso entrar em consenso com alguém sobre algo no mundo.

Para Habermas só temos acesso aos objetos por meio das expressões linguísticas e até mesmo nossas sensações são mediadas linguisticamente. Segundo ele, foi mérito de Willard Sellars a superação do "mito do dado" ou da crença na imediatidade de nosso acesso aos objetos do mundo. O significado das expressões linguísticas não depende apenas de sua relação com os objetos, mas, sobretudo, do uso ou da sua função no contexto da práxis linguística, fazendo-o passar pelo reconhecimento intersubjetivo dos sujeitos linguísticos. O conhecimento passa a ser então uma reflexão da linguagem sobre si mesma, a partir de um momento performativo (relação entre sujeitos) e proposicional (saber de objetos), mas a ênfase da racionalidade recai na esfera da força ilocucionária (função comunicativa da linguagem) dos atos de fala e na dimensão pragmática da linguagem.

Está presente aqui, nesse caso, em Habermas, uma visão nominalista ${ }^{13}$ do mundo em que a realidade se nos dá a conhecer no contexto do mundo da vida no qual já estamos inseridos enquanto membros de uma comunidade linguística de interação. Para Habermas o modelo da representação é estático e enganoso, porque sugere que o conhecimento representa os objetos do mundo e abstrai dos contextos de fala e de ação dos sujeitos. Já o modelo da facticidade é dinâmico e leva em conta os contextos das experiências, por meio do aumento de saber e da problematização e justificação discursivas. O conhecimento para Habermas é fruto de um processo de aprendizagem em que nossas práticas e intervenções são confirmadas ou negadas pela realidade (fracasso performativo) e resultado de processos genéticos naturais de aprendizagem ou processos evolucionários prévios que produziram nossas formas de vida frente aos processos culturais (naturalismo fraco).

13 OLIVEIRA, 2012a, pp. 91-92.

\begin{tabular}{|l|l|l|l|l|}
\hline Govista Dialectus & Ano 10 & n. 24 & Setembro - Dezembro 2021 & p. $12-33$ \\
\hline
\end{tabular}


Os atos de fala que pretendem validade ${ }^{14}$ estão baseados num horizonte comum de convicções e evidências inabaláveis chamado de mundo da vida que na verdade é o a priori destranscendentalizado que tem origem nos processos evolucionários da natureza por meio da aprendizagem de processos causais. No entanto, para evitar a objetivação das normas e a explicação causal das ciências naturais numa espécie de determinismo fatalista, Habermas propõe aqui a sua famosa teoria do naturalismo fraco que admite a hipótese de uma origem natural e evolucionária de nosso aparato cognitivo e cultural, mas que não assume a explicação científica de que os desenvolvimentos futuros ou processos de aprendizagens são fruto apenas de evoluções neurológicas ou biogenéticas neutras em nosso cérebro, mas dentro da perspectiva da continuidade entre natureza e cultura desenvolve uma concepção de aprendizagem evolucionista que é baseada na solução de problemas que levam a níveis de aprendizagem cada vez mais complexos (HABERMAS, 2004, p. 36-37). Frente a estas considerações, ainda assim, esta solução do naturalismo fraco parece não escapar das mesmas críticas feitas ao naturalismo forte de Quine, por exemplo, segundo M. Oliveira:

No entanto, o problema que aqui se põe mesmo para este naturalismo fraco é se ele não conduz às implicações que derivam da naturalização, desta forma, inevitável de sua concepção de linguagem e, consequentemente, das condições de possibilidade do conhecimento sociolinguisticamente gestadas nas práticas sociais (OLIVEIRA, 2019a, p. 236).

No pensamento pós-metafisico de Habermas, a própria estrutura do método transcendental sofre uma mudança radical, ele desce à terra, como ele diz, porque não é mais a consciência ou subjetividade (como ele afirma, situada no mundo inteligível), a grandeza transcendental, mas a intersubjetividade destranscendentalizada do mundo da vida que se torna a condição universal e necessária dos conhecimentos dos objetos. "A consciência transcendental perde as conotações de uma grandeza situada 'no além', no âmbito do inteligível; na forma dessublimada da práxis cotidiana comunicativa, ela desce à terra" (HABERMAS, 2004, p. 25). O sujeito transcendental se transforma agora na comunidade de sujeitos capazes de linguagem e ação e a análise dos juízos da experiência é substituída pela análise de padrões básicos de atuações regradas, ou seja, das estruturas profundas como pano de fundo das práticas do mundo vivido.

A razão agora passa a ser uma forma de justificação pública que tem como parte inerente de sua estrutura, a comunicação e as práticas dos mundos vividos como sua condição ineliminável e universal. O novo transcendental habermasiano é a intersubjetividade das regras da linguagem e da

14 Para Habermas o que está em questão não é o conteúdo das sentenças empíricas cuja validade não é acareada na fala quotidiana, mas sim, a validade das condições discursivas que é acareada para o cumprimento das pretensões de validade. Neste sentido, ele faz várias distinções entre o nível da fala ordinária e o nível do discurso; entre os objetos da experiência e os fatos que são nossas afirmações sobre os objetos (enunciados); entre sentenças e atos de fala (ações linguísticas).

\begin{tabular}{|l|l|l|l|l|}
\hline Govista Qialectus & Ano 10 & n. 24 & Setembro - Dezembro 2021 & p. $12-33$ \\
\hline
\end{tabular}



ação dos mundos vividos que capacitam os sujeitos linguísticos para a comunicação e o consenso. Neste sentido, a razão em Habermas fica limitada ao operador teórico restrito pragmático/comunicativo ${ }^{15}$ : “desde a perspectiva da razão/racionalidade comunicativa, é o caso que", e segundo Puntel, desta forma não se pode defender um pensamento universal, porque o pensamento teórico não é reduzível ao pensamento comunicativo como quer Habermas.

Para Puntel a linguagem é fundamental para articular toda e qualquer teoria filosófica a partir de sentenças expositivas com o operador teórico universal e irrestrito. As sentenças constituem uma unidade básica fundamental com outras sentenças a partir de estruturas lógicas e matemáticas que não são apenas estruturas mentais, mas dizem algo sobre algo do mundo, portanto, possuem um conteúdo informacional, um expressum que é estruturado linguisticamente. Portanto, a semântica se torna central numa teoria filosófica, pois ela articula a relação entre sentenças/proposições e mundo objetivo a partir da determinação da linguagem por meio de suas estruturas lógicas e ontológicas, tendo em vista que toda sentença possui um donde (conteúdo informacional das sentenças) e um para onde (dados do mundo objetivo) em que se dá a plena determinação da linguagem filosófica.

Elas são um nível intermediador: possuem um 'donde' por serem o expresso de sentenças; mas, têm também um 'para onde': apontam para além delas mesmas, expressam o plano ontológico. Quando plenamente determinadas se identificam com o plano ontológico. Daí o axioma básico: semântica e ontologia são os dois lados da mesma medalha (OLIVEIRA, 2020, p. 474).

Puntel critica a razão comunicativa de Habermas por ser limitada a fatores externos e aplicações da teoria, que não têm relação com sua estrutura imanente ou lógica interna que deveria ser objetiva e neutra do ponto de vista dos contextos de ação e de fala. Também critica o seu conceito de mundo da vida por limitar a reflexão ao seu aspecto pragmático e privilegiar as linguagens naturais que são em si mesmas, comunicacionais e não expositivas fundamentalmente. Dessa forma, não conseguem alcançar o objetivo de uma teoria filosófica que trabalha com sentenças declarativas com estrita função expositiva. A crítica de Puntel se refere ao operador teórico restritivo da razão comunicacional e do mundo da vida que não operam de forma irrestrita e universal ('é o caso que p'), mas estão limitados aos contextos pragmáticos de ação e a objetivos comunicacionais e emancipatórios.

Em Habermas também problemático é a questão de seu realismo que considera a realidade como uma totalidade de objetos, ${ }^{16}$ mas a que não temos acesso linguisticamente, pois temos

15 PUNTEL, 2013, p. 188.

16 HABERMAS, 2004, p. 39.

\begin{tabular}{|l|l|l|l|l|}
\hline Govista Dialectus & Ano 10 & n. 24 & Setembro - Dezembro 2021 & p. $12-33$ \\
\hline
\end{tabular}



acesso apenas às sentenças e asserções do mundo da vida, mas não aos dados do mundo objetivo, que ficariam assim numa espécie de esplêndido isolamento da linguagem como se não pudessem ser contaminados por ela. Para Puntel, isso seria um absurdo porque é como se falássemos das coisas mesmas sem ter acesso a elas, já que todo nosso acesso é linguístico, não teria sentido falar linguisticamente de entidades que são independentes da linguagem. Considerando assim, em virtude de que a linguagem é sempre dirigida ao mundo e o mundo é sempre exprimível na linguagem. O que Habermas faz aqui é uma confusão entre representar o mundo pela linguagem, que seria uma relação mentalística entre mente e mundo, e expressar o mundo pela linguagem, que não tem nada de mentalístico, mas trata-se de uma articulação teórico-linguístico da relação entre mente e mundo.

Então como conciliar a visão realista de um mundo objetivo, independente de nós com a visão da reviravolta linguística em que só temos acesso ao mundo de forma mediada? Habermas irá enfrentar este problema a partir de duas estratégias principais: a partir do fracasso performativo quando nossos discursos e práticas são confrontados ou negados pela realidade do mundo objetivo que é um pressuposto formal assumido por todos os falantes e sem o qual seria impossível fazer qualquer afirmação com sentido ou intervir nos objetos do mundo; e da análise dos termos singulares a partir da concepção nominalista de que o mundo é a totalidade de objetos sobre os quais podemos declarar algo por meio de sentenças. "Com o auxílio do emprego de termos singulares (e do quantificador existencial), pode-se esclarecer não só um conceito suficientemente abstrato de objeto, como também o sentido da existência extralinguística de objetos" (HABERMAS, 2004, p. 40). Neste sentido, os fatos ou o que declaramos acerca dos dados do mundo vigoram a partir das sentenças ou da mediação da linguagem, o que não acontece com as coisas mesmas, o que é algo totalmente incoerente para Puntel:

De acordo com a versão da semântica das linguagens naturais chamada composicional, Habermas endossa que as sentenças verdadeiras expressam fatos e os termos singulares denotam ou referem-se a objetos. Mas tanto expressar como referir-se/denotar são funções linguísticas; portanto, se os fatos são inextricavelmente entrelaçados com a linguagem porque podem ser expressos, assim também os objetos porque podem ser referidos a. (PUNTEL, 2013, p. 205).

Numa visão crítica do pensamento de Habermas, M. Oliveira identifica uma centralização da sua filosofia da linguagem na dimensão pragmática e um esquecimento da dimensão semântica ou expositiva da linguagem. "Na práxis cotidiana não podemos usar a linguagem sem agir. A própria fala se realiza no modo de atos de fala que, por sua vez, estão engastados em contextos de interação e entrelaçados com ações instrumentais" (HABERMAS, 2004, p. 244). Aqui caberia perguntar se a pragmática é a dimensão mais fundamental da linguagem para uma teoria filosófica. Deveríamos

\begin{tabular}{|l|l|l|l|l|}
\hline Govista Dialectus & Ano 10 & n. 24 & Setembro - Dezembro 2021 & p. $12-33$ \\
\hline
\end{tabular}



antes fazer uma análise dos níveis da linguagem: a) a linguagem cotidiana em que a determinação da linguagem é puramente externa e cultural e serve apenas como meio irreflexo de acesso ao mundo; b) a linguagem pragmática em que a determinação da linguagem é entendida por meio de uma determinação externa da ação dos falantes e de forma interna pela articulação de determinado contexto linguístico (tipos de linguagem); c) a linguagem semântica em que a linguagem é determinada pela referência aos objetos do mundo, ou seja, tem uma natureza informacional, designa algo, exprime algo no mundo. A ideia de determinação da linguagem como problema fundamental parte da ideia de que a linguagem é originariamente um sistema de signos indeterminados ou subdeterminados e com a plena determinação da linguagem por meio de sentenças declarativas com a forma "é o caso que p". Neste sentido teria primazia com relação à linguagem cotidiana e pragmática, pois surgiria assim como sua condição de inteligibilidade e expressabilidade dos objetos do mundo. Aqui se mostra o déficit da teoria pragmática de Habermas: "Dessa forma, a proposta de Habermas de fazer da pragmática a dimensão central da linguagem a partir de onde se articula a reflexão filosófica é marcada por um déficit teórico básico: ele não se pergunta pela condição de inteligibilidade da própria pragmática" ${ }^{17}$.

A questão que se põe aqui é entre o uso da linguagem natural que tem como principal função o entendimento entre os falantes e o uso da linguagem teórica que tem como principal objetivo a exposição de teorias por meio de sentenças declarativas com a forma "é o caso que p", e que se refere especialmente à inteligibilidade da coisa ou ao seu conteúdo semântico. A semântica aqui seria entendida como a linguagem expositiva e informacional que se refere aos dados do mundo e à sua inteligibilidade como fundamento do entendimento mútuo entre os falantes. O problema é que Habermas entende filosofia como conhecimento no sentido de uma atividade humana nos seus aspectos pragmáticos de ação e de fala, neste sentido a referência ao sujeito é irrecusável. "O mundo objetivo não é mais algo a ser retratado, mas apenas o ponto de referência comum de um processo e entendimento mútuo entre membros de uma comunidade de comunicação, que se entende sobre algo no mundo" (HABERMAS, 2004, p. 243). Neste sentido, não tem como pensar uma filosofia enquanto teoria entendida como produto de uma atividade humana que tem referência exclusiva à inteligibilidade dos dados do mundo objetivo e à sua dimensão semântica ou de expressabilidade. Portanto, a filosofia é teoria que trabalha com sentenças de natureza declarativa ou expositiva na forma do operador universal "é o caso que p", ou seja, não faz referência, nem a sujeitos, falantes ou contextos de ação e de fala. Habermas tem uma consideração apenas operacional ou de como se efetivam e funcionam as dimensões da linguagem (semântica e pragmática), mas não tem uma

17 OLIVEIRA, 2012a, p. 98.

\begin{tabular}{|l|l|l|l|l|}
\hline Govista Dialectus & Ano 10 & n. 24 & Setembro - Dezembro 2021 & p. $12-33$ \\
\hline
\end{tabular}



consideração da sua estrutura ou constituição, enquanto dimensão de expressabilidade do mundo, o que só poderia desenvolver por meio de uma nova semântica e ontologia.

\subsection{A proposta de uma Nova Metafísica do Ser Primordial}

No contexto da reviravolta linguística, a linguagem se torna um elemento central na filosofia sistemático-estrutural de Puntel, entendida enquanto teoria e totalmente explicitada em seus pressupostos linguísticos. A reviravolta linguística não significa que estamos diante de um novo objeto de estudo da filosofia ou um novo campo do saber filosófico, ou ainda, um novo tipo de corrente filosófica. Seu significado vai além das disciplinas ou campos de estudo. Diz respeito à configuração mesma da filosofia enquanto saber teórico, ou seja, tem a ver com os pressupostos irrenunciáveis de toda e qualquer teoria. Noutras palavras, a linguagem emerge como instância irrecusável de toda teoria filosófica, e a explicitação dos seus pressupostos linguísticos (lógicos, semânticos e ontológicos), tem a ver com a sua forma adequada de articulação.

Puntel entende a filosofia como uma atividade humana que se distingue das outras pelo seu objetivo, ou seja, a elaboração de teorias. Aqui temos uma distinção importante, pois para Habermas falaríamos de teorias válidas, o que para Puntel é uma questão epistemológica, e não semântica e ontológica como a questão da verdade, à qual se referem as teorias filosóficas. Para ele, é fundamental expor os pressupostos imprescindíveis de uma teoria filosófica enquanto pressupostos de uma linguagem metódica e rigorosa baseada estritamente em sentenças declarativas. Para isso, Puntel vai elaborar no início de seu empreendimento teórico, uma quase-definição de filosofia, no sentido de uma definição programática, que, portanto, apresenta um programa a ser executado como teoria das estruturas universais do universo ilimitado do discurso (PUNTEL, 2008, p. 33). Para ele, é preciso começar por expor a dimensão da teoricidade de sua sistemática-estrutural, ou seja, os pressupostos irrenunciáveis de toda e qualquer teoria que são as estruturas universais. Existem dois tipos de estruturas universais, as formais (lógicas e matemáticas) e as de conteúdo (semânticas e ontológicas).

O universo ilimitado do discurso inclui de forma abrangente todos os dados do mundo que podem ser candidatos a uma exposição teórica e o dado abrangente ou grande dado (o Ser em si mesmo) que é a dimensão mais fundamental de todas as dimensões que compreende e abrange todas as espécies e formas de ser. Por isso, a tarefa da filosofia é desenvolver uma teoria compreensiva do mundo em suas várias dimensões que trabalhe a questão das conexões entre a dimensão dos dados e a dimensão das estruturas e a dimensão originária e abarcante de ambas que é o Ser em si mesmo. Na sua sistemática do mundo, Puntel explicita as conexões ou interconexões entre as entidades do mundo

\begin{tabular}{|l|l|l|l|l|}
\hline Q Povista Qialectus & Ano 10 & n. 24 & Setembro - Dezembro 2021 & p. $12-33$ \\
\hline
\end{tabular}



em seus vários campos ou âmbitos. Aqui não estamos falando do ente enquanto ente, o que a tradição chamava de metafísica geral; mas do ente enquanto natureza, enquanto ser humano, etc. Portanto, trata-se aqui, na sistemática do mundo, de uma reestruturação do que na tradição se chamou de metafísicas especiais, ou na linguagem de Husserl, de ontologias regionais.

\subsection{A tematização da relação entre linguagem e mundo}

Numa dimensão compreensiva da realidade, temos que levar em consideração a relação entre linguagem e mundo, ou entre sujeito e objeto. Noutras palavras, temos que considerar o que é mesmo o compreender os dados da realidade a partir da linguagem? Atualmente, existem várias teorias filosóficas que pensam o nosso acesso aos dados do conhecimento. Uma delas é o realismo metafísico que entende que o compreender é determinado pela coisa a ser compreendida. Neste sentido, a realidade é pré-dada. Existe independente de nossos conceitos e teorias que têm a única função de explicá-la e descrevê-la. Aqui a linguagem não tem um lugar central na elaboração das teorias e na sua justificação ${ }^{18}$.

Outra posição é a do idealismo ou antirrealismo que tenta mostrar que todo nosso acesso aos objetos do mundo se dá dentro de esquemas conceituais ou é mediado linguisticamente. Neste sentido, a posição realista torna-se algo ininteligível. Como uma posição intermediária entre o realismo metafísico e o relativismo, temos o realismo interno de Hilary Putnam que se opõe fortemente ao que chama de perspectiva de Deus: “..., ou seja, dispor de um 'ponto de vista' capaz de abranger os dois lados do abismo ou da cesura, de modo a podermos comparar teoria e mundo e decidir se entre ambos há uma correspondência ou quando tal correspondência foi alcançada" (PUNTEL, 2008, p. 480). Neste sentido, Putnam evita uma posição que admitiria a teoria da verdade como correspondência, pois não temos como garantir a verdade de nossas teorias. Isso porque, enquanto seres finitos, não temos uma noção única e exclusiva da verdade dos enunciados e da existência das coisas independente de nossas versões e práticas limitadas. Daí porque ele defende uma perspectiva estritamente subjetiva em nosso relacionamento com o mundo, ou seja, todo e qualquer conhecimento é mediado por nossos esquemas conceituais, que nos fornecem várias versões da realidade.

18 Para Puntel a palavra justificação está no nível pragmático de fundamentação entre os falantes sobre algo no mundo, por isso, ele a distingue de fundamentação no sentido teórico ou a partir de um determinado Quadro Teórico, no qual o que valem são as definições, axiomas, regras daquele Quadro Teórico específico na sua relação com os dados do mundo. Neste sentido, ele prefere usar a palavra demonstração ou demonstração em sentido estrito e fundamentação teórica. Sobre isso, Cf. PUNTEL, 2008, pp. 67-69.

\begin{tabular}{|l|l|l|l|l|}
\hline Govista Dialectus & Ano 10 & n. 24 & Setembro - Dezembro 2021 & p. $12-33$ \\
\hline
\end{tabular}


Adriano Messias Rodrigues / Luís Alexandre Dias do Carmo

Neste sentido, o mundo só existe como algo moldado por nós (espírito/linguagem/conceitos). Por isso, o nome de realismo interno, na ótica de que a visão que temos da realidade só existe dentro de um esquema conceitual articulado por nós. Puntel pergunta se não haveria a possibilidade de existir um mundo não moldado por nós? Para ele, Putnam pretende superar o abismo entre sujeito e objeto, mas fica apenas no nível epistêmico (sujeito), e o lado do objeto (da realidade em si) serve apenas de pano de fundo para dar evidência ao mundo como é moldado por nós.

\begin{abstract}
No entanto, para Puntel, na posição do realismo interno, a dicotomia não só não é superada, mas aprofundada, pois aqui a realidade/mundo/universo só existe dentro de um esquema conceitual "articulado por nós". Persiste aqui, porém, nesta posição uma pergunta de que não podemos escapar: "se "realidade" ou "mundo" existem ou poderiam existir de alguma maneira como mundo não moldado por nós?" (OLIVEIRA, 2019a, p. 298).
\end{abstract}

Outrossim, para superar a dicotomia entre pensamento e mundo, é preciso admitir a estrutura imanente da realidade enquanto expressabilidade universal: tudo o que é objeto de uma teoria pressupõe que este seja expressável. Por conseguinte, a expressabilidade é uma estrutura do mundo e isto implica uma instância que a exprima, uma instância de expressabilidade igualmente universal (linguagem universal), sob pena de qualquer empreendimento teórico se tornar, por princípio, sem sentido e autocontraditório. Para Puntel, o problema do antirrealismo é que ele pensa a linguagem como nossa linguagem reduzindo as estruturas universais ao universo limitado das linguagens particulares do sujeito. Mesmo no caso de Humboldt apud Oliveira (2019b, pp. 29-30) quando pensa a linguagem enquanto estrutura universal do mundo, o faz na sua relação inseparável com a consciência, enquanto órgão que estrutura o pensamento, ou seja, na sua determinação pelo sujeito do conhecimento. Até mesmo a solução da filosofia pragmática, torna-se insuficiente para pensar uma linguagem na sua estruturalidade universal, pois faz referência às ações dos sujeitos.

A proposta de Puntel para a superação do dualismo entre sujeito e objeto se articula em torno de quatro teses fundamentais: primeira, a forma adequada de exposição da filosofia é a das sentenças na forma puramente teórica; segunda, a semântica e a ontologia estão fundamentalmente interconectadas; terceira, a expressabilidade constitui um momento estrutural fundamental dos entes e do Ser; quarta, a linguagem filosófica é uma linguagem expositiva. No caso, Puntel considera que:

(...) mostrou-se também que a efetiva superação do abismo, isto é, a superação que não é só afirmada de algum modo genérico, mas também concretizada em detalhes, pressupõe a aclaração de uma série de questões fundamentais. A mais importante de todas as questões diz respeito à compreensão da linguagem teórica. Essa grande temática foi abordada a partir da ideia da expressabilidade universal do mundo (do universo, do ser) (PUNTEL, 2008, pp. 548-549). 
Partindo de sua definição de filosofia enquanto teoria que se expressa a partir de sentenças declarativas, Puntel defende que a linguagem sempre é linguagem de algo e este algo só é pensável linguisticamente. A linguagem defendida pelo autor é uma linguagem filosófica, pois a linguagem natural é baseada em sentenças que se valem da lógica de predicados de primeira ordem (no caso seu instrumento formal e, no mais, radicadas numa semântica composicional), ou seja, estruturadas na relação entre sujeito e predicado. Porém, pergunta-se: quando se abstrai de todas as determinações (na ontologia composicional pensadas como atributos, ou seja, propriedades e relações) e das entidades com as quais possa entrar em relação tal entidade (no caso da ontologia composicional pensada como substância/substrato ou objeto na filosofia analítica), o que resta? Apenas um substrato (substância) sem determinação, vazio e ininteligível que é pressuposto pela semântica da composicionalidade. Puntel sobre a substância, afirma: "Se retirarmos dela todas as propriedades, relações ou estados de coisas que lhe são atribuídos, o X ainda assim subsistiria de algum modo, já que, em conformidade com o seu pressuposto, ele não é idêntico com essas determinações" (PUNTEL, 2008, p. 91). Para ele, uma entidade assim tão indeterminada e vazia, abstrata em sua identidade própria, não é inteligível e deve ser abandonada pelo filósofo que busca um maior grau de inteligibilidade para as suas teorias.

Nessa perspectiva, Puntel propõe uma nova semântica que é baseada numa versão forte do princípio do contexto de Frege o qual diz que o significado das palavras é dado pelo contexto da sentença que expressa pensamentos. Puntel interpreta este princípio a partir da primazia da sentença enquanto uma configuração de sentido e explicação dos componentes subsentenciais das asserções verdadeiras sobre os elementos do mundo (OLIVEIRA, 2020, p.475). Ele se baseia, não no princípio de composicionalidade, que compreende a sentença a partir da estrutura de sujeito e predicado, isto é, o significado da sentença é dado pela composição dos significados dos componentes subsentenciais, ou seja, sujeito e predicado, a que corresponde uma ontologia da substância; mas, em sentenças primas (a palavra "prima" quer exprimir precisamente sem a estrutura sujeito e predicado) que têm a estrutura fundada no expressum da sentença. Noutras palavras, sentenças primas significam sentenças sem a estrutura sujeito/predicado da semântica composicional. Como exemplo de sentença prima, temos a sentença, chove, que expressa uma proposição prima. Qual será então a forma adequada de uma sentença teórica, já que a mesma não pode ter a forma de sujeito e predicado? Puntel estabelece um operador lógico que é anteposto à sentença de forma implícita ou explícita como determinante de seu valor de verdade, é o caso que. No exemplo citado, a sentença na sua forma correta seria assim formulada, é o caso que chove. Onde a formalização da estrutura da sentença prima ficaria dessa forma: “(T) $(\varphi)$, sendo $(T)$ o operador teórico e $(\varphi)$ a variável de uma sentença” (HERRERO, 2012a, p. 15). Neste sentido, Puntel parte em sua semântica de duas teses fundamentais:

\begin{tabular}{|l|l|l|l|l|}
\hline Govista Qialectus & Ano 10 & n. 24 & Setembro - Dezembro 2021 & p. $12-33$ \\
\hline
\end{tabular}


a) a implicação mútua ente semântica e ontologia; b) o caráter insustentável da ontologia substancialista (ininteligibilidade do conceito de substância). Dessa forma, exige-se uma nova ontologia. E pela implicação mútua entre ontologia e semântica, também uma nova semântica em que Puntel se utiliza em sua exposição de sentenças na estrutura sintática de sujeito/predicado que é o que usamos na linguagem quotidiana fazendo, porém, uma leitura semântica a partir do princípio do contexto.

\subsection{A linguagem originária enquanto dimensão de expressabilidade do Mundo}

Diante do contexto de abismo (gap) entre linguagem e natureza (pensamento e mundo) que marca a postura pós-metafísica de Habermas, Puntel propõe uma teoria abrangente e universal que considere não apenas aspectos isolados da realidade ou campos do saber, mas a realidade como um todo ou na sua estruturalidade imanente. Por isso, pergunta como pode um sujeito contingente e limitado como o ser humano, que faz um uso situado de linguagens particulares, refletir sobre a realidade como um todo ou em suas características imanentes universais? Para pensar a realidade de forma universal, é necessário determinar um critério linguístico universal e repensar a centralidade dada ao sujeito pela filosofia moderna da subjetividade.

Primeiro, temos que distinguir entre duas formas de linguagens. Uma que é histórica, contingente e bem determinada, enquanto signos linguísticos e que é uma produção humana e que tem como referencial fundamental, o sujeito linguístico ou ação dos falantes. E outra, que é a linguagem no sentido maximal ou enquanto estrutura absolutamente universal, enquanto expressabilidade universal do ser em seu todo (OLIVEIRA, 2019b, pp. 34-36). Aqui a linguagem emerge como uma dimensão da inteligibilidade do todo da realidade que é em si mesma expressável e que logicamente demanda de uma instância expressante. Neste sentido, a linguagem é coextensional aos dados do mundo (entes) e ao ser na sua expressabilidade imamente. Para Puntel, a coextensionalidade linguística não se refere apenas aos entes como pensava a antiga ontologia clássica, mas também o ser que é expressável linguisticamente. E por isso, ele fala de universo ilimitado do discurso. Noutras palavras, o real é expressável, não só o ente, mas, sobretudo, os entes são expressáveis na medida em que são. Neste sentido, não existe para Puntel uma identificação entre os entes e o Ser. Os entes são, enquanto abarcados pelo Ser, mas não são o Ser. Por essa razão se fala justamente de Ser primordial e há distinção estrita entre ontologia (teoria dos entes) e metafísica primordial (teoria do Ser em si mesmo e em seu todo). Por isso que sua teoria deve ser entendida não apenas como ontologia, mas como metafisica do Ser Primordial.

\begin{tabular}{|l|l|l|l|l|}
\hline Govista Qialectus & Ano 10 & n. 24 & Setembro - Dezembro 2021 & p. $12-33$ \\
\hline
\end{tabular}


Puntel entende a linguagem como um "sistema semiótico composto de uma quantidade infinita não enumerável de expressões" (PUNTEL, 2008, p. 497) ou que compreende todos os dados do universo do discurso em sua estruturalidade imanente. É essa linguagem que ele denomina de linguagem originária, enquanto instância expressante da inteligibilidade do mundo em seu todo. $\mathrm{O}$ autor chega a este conceito de linguagem a partir da tese de que todo empreendimento teórico pressupõe a expressabilidade do que trata, o que exige como contrapartida uma instância de expressabilidade universal fundamental da expressabilidade universal que entende a linguagem como dimensão expressante do real nas suas determinações imanentes. O que significa que a filosofia enquanto atividade expositiva sobre o mundo se articula de forma linguística. Neste sentido, a linguagem se torna o elemento central de toda a teoria filosófica. Puntel defende que, nas estruturas linguísticas, pode-se ler a estruturalidade do mundo. Ou seja, as estruturas lógicas, semânticas e ontológicas da linguagem são estruturas do mundo. Nesta pesquisa, defende-se a centralidade desta tese ontológica para a constituição do conceito de linguagem e para pensar a teoria sistemáticoestrutural punteliana que tem como fundamento uma nova concepção de linguagem nas suas bases semânticas e ontológicas.

Nessa perspectiva, a filosofia punteliana irá refletir sobre a conexão universal ${ }^{19}$ entre as estruturas universais e o ser objetivo, enquanto elemento comum de todas as conexões entre as diversas esferas da realidade, a partir de uma visão da estrutura das sentenças declarativas que não têm relação com o sujeito, enquanto determinante fundamental da teoria que se expressa no operador lógico: é o caso que assim e assim. Neste sentido, o que está em primeiro plano é a linguagem enquanto expressante universal do ser nas suas estruturas lógicas, semânticas e ontológicas.

O entendimento punteliano concebe o Ser Primordial não como a soma de todos os entes ou como algo além deles, mas como uma realidade que é co-articulada em cada sentença declarativa a partir da dimensão da expressividade universal do ser que se manifesta como linguagem. Na sistemática compreensiva é exposto, em primeiro lugar, o ser em si mesmo (metafísica), ou seja, nas suas características imanentes de inteligibilidade, coerência universal e expressabilidade (características teóricas) e bondade, perfeição e beleza (características práticas).

Em um segundo momento da sistemática do mundo é exposto o ser no seu todo, ou como ente enquanto tal (ontologia), ou seja, nas suas relações com os entes nas suas várias dimensões,

19 Trata-se aqui da dimensão que possibilite pensar a diferença e a relação entre o mundo dos sujeitos e o dos objetos, uma dimensão abarcante e originária que abrange os dois polos da realidade e que lhes dê sentido e fundamento. $\mathrm{O}$ conceito oniabrangente que permite pensar a relação entre os dois termos de maneira não reducionista que seria o conceito de Mundo (com 'M' maiúsculo) que seria a dimensão abarcante que inclui tanto o mundo objetivo, natural como cosmo ou processo evolutivo físico-biológico, quanto o mundo da vida como dimensão da comunicação e da ação. Sobre isso, Cf. PUNTEL, 2015a, p. 114. 

políticas, sociais, históricas, éticas, estéticas, etc. Neste ponto, Puntel irá fazer uso da teoria das modalidades (necessidade, possibilidade e contingência) para combater a tese onicontingentista, cuja posição implica a possibilidade do nada absoluto, um conceito autocontraditório segundo Puntel: “Se absolutamente tudo - e, assim, a própria dimensão do ser-fosse contingente, dever-se-ia assumir a possibilidade do nada absoluto. - Porém, ocorre que o nada absoluto não é possível. - Portanto, nem tudo, isto é, nem toda a dimensão do ser é contingente" (PUNTEL, 2008, p. 593). O que ele defende é que existe uma dimensão necessária e uma dimensão contingente no Ser Primordial, entendido como bidimensionalidade. Essa é uma grande novidade da teoria de Puntel e grande conquista em termos de determinação de seu quadro referencial teórico, ou seja, a recuperação da teoria modal a partir das correntes mais modernas da atualidade.

\section{CONCLUSÃO}

A pesquisa sobre as questões metafísicas tem se intensificado nos últimos anos, especialmente na filosofia analítica. Apesar disso, não temos uma visão abrangente ou universal de sua temática, devido à separação ontológica (que provém de uma filosofia que se entende fundamentalmente enquanto epistemologia, a filosofia transcendental) entre sujeito e objeto. Neste sentido, a filosofia transcendental ainda possui uma influência determinante no método filosófico das correntes filosóficas, especialmente o realismo epistêmico-pragmático de Jürgen Habermas. A filosofia de Puntel tem a proposta de superar este abismo conceitual entre linguagem e mundo e pensar de forma sistemática as questões suscitadas pela filosofia analítica (no nível das estruturas) e pela filosofia fenomenológico-hermenêutica de Heidegger (no nível do conteúdo), a partir de uma teoria metafísica do Ser Primordial. Dessa forma, pretendíamos demonstrar que a filosofia sistemáticoestrutural de Puntel se configura como o quadro referencial teórico mais abrangente e universal para tratar com propriedade dos problemas do naturalismo e do realismo suscitadas pela reflexão intersubjetiva e dualista de Jürgen Habermas. Tendo em vista que ele não consegue substituir o ponto de vista da subjetividade isolada de Kant e Husserl por um novo modelo de intersubjetividade, pois para Puntel, uma filosofia da intersubjetividade continua sendo uma variante da filosofia da subjetividade, e, portanto, o dualismo entre sujeito e objeto permanece. Neste sentido, a posição de Habermas ainda se configura no horizonte de filosofia da subjetividade transcendental, pois assume como elemento determinante de sua pragmática formal, a organização de uma filosofia da subjetividade transcendental, mesmo quando entendida como uma estrutura fundamental na esfera da comunicação.

\begin{tabular}{|l|l|l|l|l|}
\hline Q Rovista Dialectus & Ano 10 & n. 24 & Setembro - Dezembro 2021 & p. $12-33$ \\
\hline
\end{tabular}


Puntel insere-se numa tradição de mais de dois mil anos que entende a filosofia enquanto teoria abrangente que trabalha as estruturas fundamentais da realidade enquanto tal. Obsta que, na situação atual da filosofia, existe uma fragmentação do saber causada pelo abismo entre o conhecimento e mundo, sujeito e objeto que foi inaugurado de forma sistemática por Kant; o que, por sua vez, influencia várias correntes da filosofia atual como o pensamento pós-metafísico do filósofo alemão Jürgen Habermas. A proposta filosófica de Puntel pretende superar esta postura epistemológica, por meio de uma filosofia sistemático-estrutural sobre o Ser como tal e em seu todo, ou seja, nas suas relações com os entes, a partir de um quadro referencial teórico plenamente explicitado e justificado diante das teorias e hipóteses mais recentes da filosofia atual. Puntel pretende pensar a partir da tradição filosófica, mas dentro do contexto teórico aberto pelas filosofias contemporâneas, uma nova forma de articulação da filosofia enquanto tal.

Neste artigo apresentamos a contraposição entre dois modelos de pensar a realidade, o modelo pós-metafísico da pragmática formal de J. Habermas e o modelo de uma nova metafísica do Ser Primordial de Lorenz B. Puntel. A questão central aqui é a primazia da pragmática habermasiana que restringe a realidade, aos contextos dos mundos vividos e a sua forma de justificação que consiste nas acareações das pretensões de validade discursivas dos sujeitos de ação e de fala. Neste sentido, o operador lógico utilizado é o da razão comunicativa que não dá conta de uma visão universal e englobante da realidade na explicitação das coisas mesmas em sua inteligibilidade e coerência universais. Noutras palavras, Habermas limita as potencialidades da razão humana e o campo temático da filosofia. Ele é vítima das críticas céticas e relativistas, pois ao mesmo tempo que repõe as questões advindas do realismo e do naturalismo, não consegue enfrentá-las satisfatoriamente. Assim não consegue superar o modelo da filosofia transcendental em que o sujeito está situado num verdadeiro abismo epistêmico com relação às coisas do mundo, que ele não pode conhecer, mas apenas pressupor como algo comum e independente da linguagem teórica.

O que Puntel pretende fazer é recuperar a centralidade da semântica em relação à pragmática, pois para ele é por meio das sentenças que falamos sobre algo no mundo, portanto toda sentença tem um conteúdo informacional, ou seja, aponta para uma realidade além de si que é a coisa mesma impregnada linguisticamente. Puntel irá partir das linguagens naturais, mas desenvolverá uma linguagem artificial, específica de uma teoria filosófica que é a sentença declarativa que opera de forma simpliciter, ou seja, que não tem referência a sujeitos, contextos de ação e de fala, mas apenas à coisa mesma em sua inteligibilidade (é o caso que é assim e assim).

Puntel considera a semântica como dimensão fundamental para pensar a realidade, daí a sua famosa expressão de que a semântica e a ontologia são os dois lados da mesma moeda. Neste sentido, ele irá superar a postura dualista da filosofia transcendental, pois linguagem e mundo não

\begin{tabular}{|l|l|l|l|l|}
\hline Gonista Dialectus & Ano 10 & n. 24 & Setembro - Dezembro 2021 & p. $12-33$ \\
\hline
\end{tabular}



são mais grandezas opostas, mas elementos do mundo co-originários e impregnados linguisticamente. Quanto à questão ontológica do naturalismo e a questão epistemológica do realismo, Puntel propõe uma nova semântica que substitui o conceito ininteligível de substância pelo conceito de configuração dos fatos primos que quando são verdadeiros correspondem aos objetos do mundo. Também, propõe uma nova ontologia que tematize as estruturas lógicas, semânticas e ontológicas a partir da centralidade da linguagem enquanto dimensão de expressabilidade do Ser em si mesmo e em seu todo.

\section{REFERÊNCIAS}

FRANÇA, Clístenes Chaves de. Pragmática formal, verdade e realismo: do conceito epistêmico à indeterminação da verdade em Jürgen Habermas. Dissertação, UFC. Fortaleza, 2017.

HABERMAS, Jürgen. Conhecimento e interesse. São Paulo: Editora Unesp, 2014.

. Verdade e justificação: ensaios filosóficos. São Paulo: Loyola, 2004.

. Pensamento pós-metafísico. Rio de Janeiro: Tempo Brasileiro, 1990.

O discurso filosófico da modernidade. São Paulo: Martins Fontes, 2002.

HEIDEGGER, Martin. Ser e Tempo. Tradução revisada de Márcia Sá Cavalcante Schuback. Petrópolis, RJ: Vozes; Bragança Paulista, SP: Editora Universitária São Francisco, 2011.

HERRERO, Javier F. O desafio que a teoria sistemático-estrutural de Puntel coloca à filosofia atual (AULA INAUGURAL). Kriterion, Belo Horizonte, n. 125 (2012a): 7-27.

V. 39 N. 124 (2012b): 205-236.

KANT, I. Crítica da Razão Pura. Tradução: Alexandre Morujão e Manoela dos Santos. Lisboa: Fundação Calouste Gulbenkian, 2008.

KRIPKE, Saul. Naming and Necessity. Oxford: Blackwell, 1972.

LOUX, Michael J. Metaphysics: a contemporary introduction. New York and London: Routledge, 2006.

McDOWELL, John. Mente e mundo. Tradução: João Vergílio Gallerani Cuter. São Paulo: Idéias \& Letras, 2005.

OLIVEIRA, Juliano Cordeiro da Costa. Secularismo e religião na democracia deliberativa de Habermas Da pragmática ao déficit ontológico e metafísico. Porto Alegre, Editora Fi; Teresina, EDUFPI, 2018.

OLIVEIRA, Manfredo Araújo de. A metafísica do ser primordial: L. B. Puntel e o desafio de repensar a metafísica. São Paulo: Loyola, 2019a.

\begin{tabular}{|l|l|l|l|l|}
\hline Govista Qialectus & Ano 10 & n. 24 & Setembro - Dezembro 2021 & p. $12-33$ \\
\hline
\end{tabular}



A ontologia em debate no pensamento contemporâneo. São Paulo: Paulus, 2014. Paulo: Paulus, 2012a.

Antropologia filosófica contemporânea: subjetividade e inversão teórica. São

\section{Loyola, 2006.}

Reviravolta linguístico-pragmática na filosofia contemporânea. São Paulo:

- Teoria do ser primordial como tarefa suprema de uma filosofia sistemáticoestrutural. Síntese - Rev. de Filosofia v. 39, n. 123 (2012b): 53-79.

Se, como e com que pressupostos chega a filosofia ao tema "Deus": a proposta da Metafísica Primordial. Síntese - Rev. de Filosofia, v. 42, n. 134 (2015): 475-501.

149 (2020): 469-501.

. A nova metafísica e a compreensão da religião. Síntese - Rev. de Filosofia v. 47, n.

. Centralidade da Linguagem e a Nova Proposta de Articulação da Teoria Filosófica.

In: __ _ SOUZA, Marcus José Alves de; LIMA FILHO, Maxwell Morais de (Orgs.).

Escritos de Filosofia III: Linguagem e Cognição [recurso eletrônico] - Porto Alegre, RS: Editora Fi, 2019b, pp. 14-39. Disponível em: http://www.editorafi.org.

PUNTEL, Lorenz B. Estrutura e Ser. Um quadro referencial teórico para uma filosofia sistemática. Trad. Nélio Schneider. São Leopoldo: Ed. UNISINOS, 2008.

. Ser e Deus. Um enfoque sistemático em confronto com M. Heidegger, É. Lévinas e

J. -L. Marion. Tradução: Nélio Schneider. São Leopoldo: Ed. UNISINOS, 2011.

- A filosofia como discurso sistemático: diálogos com Emmanuel Tourpe sobre os fundamentos de uma teoria dos entes, do Ser e do Absoluto. Tradução: Nélio Schneider. São Leopoldo: Ed. UNISINOS, 2015a.

. O pensamento pós-metafísico de Habermas: uma crítica. Síntese - Rev. de Filosofia v. 40, n. 127 (2013): 173-223.

. A filosofia e a questão de Deus: um novo enfoque sistemático. Síntese - Rev. de

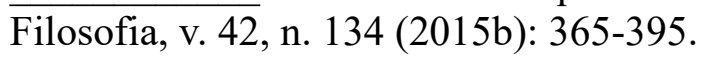

. A totalidade do Ser, o Absoluto e o tema "Deus": um capítulo de uma nova metafísica. In: __ IMAGUIRE, Guido; ALMEIDA, Custódio Luís S. de; OLIVEIRA, Manfredo Araújo de (Orgs.). Metafísica Contemporânea - Petrópolis, RJ: Vozes, 2007, pp. 191-222.

PUTNAM, Hilary. Mind, Language and Reality. Cambridge: Cambridge University Press, 1975.

QUINE, W. V. Theories and Things. Cambridge (MA), London: Harvard, 1981.

RORTY, Richard. A filosofia e o espelho da natureza. Tradução: Antônio Trânsito. Rio de Janeiro: Relume-Dumará, 1994.

\begin{tabular}{|l|l|l|l|l|}
\hline Govista Qialectus & Ano 10 & n. 24 & Setembro - Dezembro 2021 & p. $12-33$ \\
\hline
\end{tabular}


SELLARS, W. Empirismo e filosofia da mente. Com uma introdução de Richard Rorty e um guia de estudos de Robert Brandom. Petrópolis: Vozes, 2003.

TARSKI, Alfred. A concepção semântica da verdade. Tradução de Celso Braida. São Paulo Editora Unesp, 2007.

WITTGENSTEIN, L. Tratado Lógico-Filosófico e Investigações Filosóficas. Tradução e prefácio de M. S. Lourenço. Lisboa: Fundação Calouste Gulbenkian, 2008. 